\title{
EMANCIPACIÓN SOCIAL, IGUALDAD Y DISCURSO ANTIOLIGÁRQUICO: MALAQUÍAS CONCHA Y SU VISIÓN DE LA DEMOCRACIA EN CHILE ${ }^{1}$
}

\author{
SOCIAL EMANCIPATION, EQUALITY AND ANTI-OLIGARCHIC \\ DISCOURSE: MALAQUIAS CONCHA AND HIS VISION OF \\ DEMOCRACY IN CHILE
}

\author{
Gabriel Cid \\ Universidad San Sebastián \\ Facultad de Derecho y Gobierno, Instituto de Historia \\ Lota 2465, Providencia, Santiago, Chile \\ gabriel.cid@uss.cl
}

\begin{abstract}
RESUMEN
El artículo examina la conceptualización de la democracia de Malaquías Concha a fines del siglo XIX. El intelectual público más relevante del Partido Democrático contribuyó al cuestionamiento del discurso liberal, mediante una crítica antioligárquica, que reposicionó el contenido clasista de la democracia, y del despliegue de nuevos referentes conceptuales que singularizaron el discurso democrático de ese nuevo partido, entre los que se encontraban
\end{abstract}

Proyecto Fondecyt 11160298, "El espectro del pueblo: la conceptualización de la democracia en Chile, 1841-1887". 
las nociones de igualdad, movimiento obrero, derechos sociales, Estado providencia y emancipación social.

Palabras clave: democracia, Malaquias Concha, igualdad, movimiento obrero, partido democrático.

\begin{abstract}
This article examines Malaquías Concha's conceptualization of democracy at the end of the 19th century. The most relevant public intellectual of the Democratic Party contributed to the questioning of the liberal discourse with his anti-oligarchic critique that repositioned the class content of democracy and the deployment of new conceptual referents that singled out the democratic discourse of the new political party, among which where the notions of equality, labor movement, social rights, the welfare state, and social emancipation.
\end{abstract}

Keywords: Democracy, Malaquias Concha, Equality, Labor Movement, Democratic Party.

Recibido: 02/11/2019

Aceptado: 15/01/2020

\title{
I. Malaquías Concha y la Redefinición de la DEMOCRACIA EN TIEMPOS DE LA CUESTIÓN SOCIAL
}

Para mi la democracia es un ideal, es un sistema de gobierno del pueblo para y por el pueblo, en que domina la justicia y la igualdad. (Malaquías Concha, El Demócrata, 23 de febrero de 1888)

Los años posteriores a la Guerra del Pacífico fueron importantes en la conformación de la fisonomía que marcaría el devenir nacional. En efecto, el proceso de expansión territorial del Estado chileno tanto al sur como al norte fue paralelo a la instalación en el debate público de la cuestión social, expresión introducida por el médico Augusto Orrego Luco (1884) para denunciar la pauperización de las condiciones de vida de los sectores populares en un contexto en el que podía constatarse también la aristocratización 
del ethos de la clase dirigente nacional, posibilitada por la riqueza salitrera (Barros y Vergara 2007). En aquellos años, el movimiento obrero adquiere una fisonomía más moderna, expresada en la multiplicación de acciones reivindicativas, una capacidad asociativa mayor y un contenido clasista en su autoconciencia más acentuado (Grez, "Transición”).

Por sus implicancias y proyecciones, la politización de la cuestión social fue de cierto modo inevitable. En efecto, la resolución parcial de las querellas doctrinarias producto de la sanción de las leyes laicas a inicios de la década de 1880 hizo que el clivaje clericalismo/anticlericalismo comenzara a perder fuerza, instalándose uno de clases con el surgimiento del Partido Democrático (Scully 73; Valenzuela 29-38). Formado por la confluencia de sectores artesanales -que comenzaron a politizar sus demandas durante la década de 1870 - y por sectores jóvenes desencantados de su militancia en el Partido Radical -que creían haberse estancado políticamente en sus querellas con el catolicismo-, el Partido Democrático procuró canalizar el descontento de los sectores populares dentro del sistema de partidos (De Petris; Grez, El Partido). Y lo hizo asumiendo una clara postura clasista -expresada en la composición de sus bases- y con una serie de propuestas tendientes a profundizar los aspectos igualitarios del régimen democrático.

En este escenario, la figura de Malaquías Concha resultó central en el proceso de redefinición del concepto de democracia en el Partido Democrático (en adelante PD), del cual será uno de sus miembros fundadores y su intelectual público más destacado. Oriundo de Linares, Concha estudió leyes en la Universidad de Chile y se tituló como abogado en 1880. Debido a su interés en las llamadas cuestiones obreras, publicó El seguro de vida (Concha 1883), donde subraya la importancia del ahorro permanente para los trabajadores. Aunque inicialmente militó en el Partido Radical, a fines de 1887 se desvincularía para formar parte del PD. En sus filas llegó al Parlamento, escogido diputado durante tres períodos entre 1897 y 1918, para luego pasar al Senado representando a Concepción en 1918. Por su peso intelectual y su trayectoria política, no sorprende la pronta canonización que gozó su figura dentro de sus filas, siendo tipificado 
como la encarnación de los valores del PD, llamándosele el "Padre de la Democracia Chilena" (Bañados 8; Godoy; Soto; Turri).

Paradójicamente, los estudios sobre Concha han quedado circunscritos en el registro biográfico laudatorio de sus correligionarios, o bien, desde una perspectiva más imparcial en términos historiográficos, como uno de los intelectuales públicos más relevantes de la cuestión social, especialmente a inicios del siglo XX (Yáñez 56-8; Nicholls; Cruzat y Tironi 144-7). Este artículo se enfoca en una arista clave de la trayectoria pública de Concha que paradójicamente ha sido inexplorada: la redefinición del concepto de democracia como sustento ideológico que orientaría el trabajo político del PD. En efecto, esta investigación plantea que la reflexión de Malaquías Concha sobre la cuestión social debe ser pensada en un proceso ideológico mayor, que es la preocupación por las condiciones materiales de posibilidad de una democracia moderna en un país socialmente desigual como Chile. En ese registro, sus aproximaciones al problema de la cuestión social son tributarias de su reflexión conceptual sobre la democracia, utilizada en sus escritos como un concepto aglutinante de sus posicionamientos políticos.

La tesis que orienta este texto es que el trabajo intelectual de Malaquías Concha respecto del concepto de democracia es propio de lo que Skinner (67) llama innovador ideológico, es decir, aquel actor que por medio de una serie de recursos retóricos resignifica el lenguaje y otorga nuevos sentidos morales a conceptos evaluativos tradicionales. Como pensador político, Concha contribuyó de manera decisiva al proceso de ideologización (Koselleck, "Un texto" 97) de la democracia operado en el seno del PD, es decir, sometió al concepto a un proceso de abstracción creciente, convirtiéndolo en un singular colectivo, a una expresión formulada como la DEMOCRACIA -así con mayúsculas-, tornando el concepto en una palabra con vida propia, en tanto actúa, hace, permite, etcétera. La ideologización de la democracia fue también de la mano de su politización, proceso que permitiría diferenciar los usos y significados que el PD confirió a uno de los conceptos nodales del republicanismo decimonónico, acentuando así las diferencias respecto de los significados posibles que el liberalismo le había conferido. En efecto, y siguiendo lo planteado en términos teóricos por Michael Freeden (75-91), 
el trabajo de Malaquías Concha en el PD consistió de conjurar el carácter inevitablemente polisémico de la democracia -mediante un esfuerzo de despolemizar sus sentidos- y establecer nuevos conceptos adyacentes que limitarían y singularizarían su semántica para sus correligionarios, como las nociones de igualdad, pueblo, oligarquía, derechos sociales, Estado providencia y emancipación social.

Así, mediante el análisis de una serie de fuentes -entre las que se cuentan artículos de prensa, folletos, libros e intervenciones parlamentarias-, este texto indaga en la conexión de dichos conceptos en el marco del discurso democrático defendido por Malaquías Concha. En primer lugar, se conecta la reflexión de este autor con los usos semánticos del concepto de democracia en la segunda mitad del siglo XIX, para luego examinar su contraposición ideológica con la oligarquía. En segundo lugar, se aborda el rol que jugará el sintagma de emancipación social como parte del proyecto democrático del PD, y su vínculo con la igualdad como condición de existencia de la convivencia democrática. Por último, se verá la nueva conceptualización del Estado llevada a cabo por Concha y el papel que debería desempeñar en la institucionalización del conflicto de clases y su morigeración mediante el despliegue de una legislación social moderna.

\section{Democracia y discurso antioligárQUico}

En noviembre de 1887 se reunieron en el salón de la Sociedad Filarmónica de Obreros de Santiago unas setenta personas, entre obreros, artesanos y jóvenes radicales que aprobaron la idea de Malaquías Concha de constituir un nuevo partido político. El programa del Partido Democrático declaraba como objetivo principal "la emancipación política, social y económica del pueblo”, para lo que se proponían una serie de medidas, entre las que se contaban la instrucción obligatoria y gratuita, la supresión de la guardia nacional, un rol más preponderante del Estado en la asistencia pública y un enfoque proteccionista en términos económicos (El Ferrocarril, Santiago, 29 de noviembre de 1888). La declaración de la nueva agrupación política 
liderada intelectualmente por el abogado linarense establecía un vínculo profundo entre democracia y pueblo, relación semántica que, aunque filológicamente obvia, en el contexto sociopolítico del surgimiento del PD, resultaba innovadora en el escenario nacional, sobre todo en términos de su institucionalización partidista.

En efecto, las singularidades de la redefinición conceptual de la democracia llevada a cabo por Malaquías Concha al alero del PD resultan más claras cuando se insertan en el discurso hegemónico sobre democracia representativa elaborado por el liberalismo desde la década de 1860 . Sintetizando una discusión compleja, puede afirmarse que el proceso posterior a la guerra civil de 1859, y el ascenso de la Fusión Liberal-Conservadora al poder implicó un énfasis en la conciliación de los intereses partidistas opuestos al autoritarismo. Así, los sectores más próximos al ala radical del liberalismo fueron morigerando sus expectativas de cambio sociopolítico, evitando en adelante -tras las traumáticas derrotas de 1851 y 1859- hacer estos cambios por canales diferentes a los institucionales (Jocelyn-Holt). Estos cambios contextuales permiten entender las nuevas dimensiones que adquirirá el concepto de democracia. En efecto, y a diferencia del momento anterior (Cid), los usos del concepto no remitirán al debate sobre los límites de la participación popular en la esfera pública, centrando la atención en el perfeccionamiento de los mecanismos del régimen representativo: la discusión sobre la democracia se trasladó desde el espacio del asociacionismo político-artesanal a la arena del debate parlamentario. Así, el énfasis en las dimensiones procedimentales de la democracia aproxima esta discusión hacia lo que la literatura llama democracia protectora, típica de la democracia liberal (Held 93-124; Macpherson 37-61).

En ese registro, la agenda de reforma constitucional desplegada desde fines de la década de 1860 tenía como foco la limitación jurídica del poder, el reforzamiento del Estado de derecho y la sanción de libertades civiles básicas para el Estado liberal (Salazar 79-91). Esta agenda se expresó durante la década de 1870 en la sanción de una serie de reformas, que incluían la supresión de la reelección presidencial y de los poderes de emergencia, tolerancia religiosa, libertad de prensa y libertad de asociación, entre otros 
(Meynet; Donoso 317-51). En términos interpretativos, sugiero que el mismo énfasis en los derechos individuales de la agenda del liberalismo supuso una creciente devaluación de la potencia colectiva del pueblo sociológico en el imaginario democrático, y su reemplazo por la noción de pueblo-principio, para ponerlo en términos de Rosanvallon (Lepeuple). Esta nueva conceptualización del pueblo, atomizado e individualista, era al mismo tiempo causa y consecuencia de este énfasis en la dimensión constitucional de la democracia y la invisibilización del pueblo como sujeto colectivo. La elitización del proceso de cambio político de la época, impulsado desde el Congreso y por el grupo de notables agrupado en torno al Club de la Reforma (Estellé), dan cuenta de este proceso de distanciamiento creciente de la dimensión sociológica de la democracia.

Este tipo de discurso en torno a la democracia comenzó a mostrar sus fisuras desde fines de la década de 1870. Por una parte, es posible constatar un proceso de repolitización del movimiento popular urbano con nuevas formas asociativas, una creciente alza de las huelgas, en especial tras la Guerra del Pacífico, y una mayor autonomización en la elaboración de un discurso democrático alternativo al emitido por los partidos políticos tradicionales (Goicovic y Corvalán; Grez, De la regeneración 633-52). Por otra, el estallido de la cuestión social evidenciaría el desgaste del discurso liberal de la democracia constitucional, reconceptualiza y recupera la dimensión más radical de su semántica, al enfatizar su dimensión igualitaria con un marcado hincapié en el rescate del contenido clasista inherentemente asociado a la noción de soberanía popular.

Esta tarea la asumirá Malaquías Concha como portavoz del trabajo intelectual operado en el PD. Esta labor debe ser entendida desde una perspectiva crítica hacia los peligros de que la visión liberal de la democracia -necesaria en su momento histórico- terminara agotando su potencial político liberador, al recluirse en el marco puramente procedimental o circunscribirse a un mero mecanismo de selección de élites que, inevitablemente, la conducirían hacia lo que la literatura llama la democracia blanda (Barber). En este registro, la preeminencia de tal discurso político en la constitución de la república había eclipsado el ideal democrático para someterlo al dominio de facto 
ejercido por la oligarquía local. Si para el liberalismo de mediados de siglo el concepto contrario de la democracia era el autoritarismo -encarnado institucionalmente en la carta de 1833-, para Concha lo será la oligarquía, que mediante una contraposición sistemática permitiría iluminar el sentido de la democracia manejado por el $\mathrm{PD}^{2}$.

En "La democracia en Chile bajo el punto de vista social, político y económico", Concha profundizó las bases ideológicas del PD. Allí, desde una perspectiva sociológica de la democracia como forma de relación social y no como procedimiento, denunció que desde una mirada histórica se podía constatar que el sistema representativo era en realidad una pantalla, una institucionalidad funcional a los intereses de la oligarquía (también llamada bancocracia) que había terminado beneficiándolos con la formulación de leyes. Este era un aspecto crucial en la visión democrática de Concha: la potestad soberana del pueblo había sido desplazada por la de la élite, usurpando así la voz del pueblo. Por eso, sostenía, "privados del ejercicio legal y correcto de nuestra soberanía, hemos venido a convertirnos de pueblo soberano en parias de la oligarquía" (La Discusión, Chillán, 20 de marzo de 1888).

La recuperación de dicha potestad pasaba por la autonomización política de los sectores populares respecto de las clases dirigentes, lo que los guiaría a construir su propia agenda política y su propio partido, de modo de emanciparse "de la triple tutela a la que le condenan la teocracia religiosa, la oligarquía política, y el predominio de los propietarios del suelo y del capital". Porque no era en el marco del liberalismo, el radicalismo o el conservantismo donde los sectores populares podrían canalizar sus demandas, pues todos estaban conformados "por la aristocracia prepotente". El "estandarte de la democracia" debía ser levantado por los mismos obreros, que debían conformar su propia asociación. En definitiva, había llegado para Concha el momento de construir "una política propia de los obreros, por los obreros, para los obreros” (El Demócrata, Concepción, 23 de febrero de 1888).

La noción de concepto contrario la tomo de Koselleck (Futures Past 155-91). 
Bajo la reinterpretación de la historia de Chile a la luz de este clivaje de clases, Concha sostenía que la postergación de los intereses de los sectores populares en favor de la acumulación de los diferentes capitales por la clase dirigente era tan antigua como la república misma, en tanto hundía sus raíces en la independencia. La clase dirigente, de facto, fue elitista en términos de la conducción política del proceso, cuestión que en el mediano plazo tendría consecuencias decisivas. En El programa de la democracia, en el comentario detallado sobre la convención de julio de 1889, Concha señaló:

Formóse pues, necesariamente una oligarquía compuesta de propietarios, de los vecinos más acaudalados, a los cuales se han venido agregando más tarde las notabilidades de la ciencia, de la industria, del comercio y del arte del gobierno, construyendo todos una burguesía de extracción republicana que se titula a sí misma clase dirigente, mezcla abigarrada de plutócratas, burócratas y teócratas que con los nombres de liberalismo y conservantismo vienen perpetuándose en el poder. (17-8)

Estos dos polos sociales, que eran al mismo tiempo dos extremos políticos, permitían entender la dinámica republicana del siglo XIX. Por un lado, se encontraban las castas privilegiadas, "llámense teocracias, aristocracias u oligarquías" y, por otro, el pueblo, entendido como la mayoría ciudadana del país, que, de manera sintomática, el secretario del PD muchas veces homologaba a la democracia propiamente tal (Concha 13). Desde una perspectiva que conceptualizaba la política a partir del registro del conflicto y no de la óptica del acuerdo, el estallido de la cuestión social había dejado en evidencia el agotamiento del clivaje religioso ("Damos la espalda a las luchas religiosas para mirar de frente el porvenir material y científico de la república”, La Discusión, 1 de noviembre de 1888) y anunciaba el surgimiento de un nuevo conflicto, que revestía de urgencia el trabajo intelectual por dotar de un nuevo significado a la democracia. Como declaraba en uno de los tantos meetings convocados por el PD en aquellos años: 
La lucha se traba en estos momentos entre la oligarquía, que es el privilegio de unos pocos, y la democracia que es gobierno de todos; entre la autoridad que se apoya en la fuerza y la libertad que se basa en el derecho, entre el pueblo que trabaja y que produce, y el usurero que lo explota y acapara riquezas, entre las abejas que elaboran la miel y los zánganos que la roban; entre los que nos insultan con su molicie, desde dorado palacio, y el pobre que muere de hambre y de frío en el estrecho y miserable tugurio [...] lucha gigantesca del oprimido contra el opresor, del trabajo contra el capital, de la igualdad contra el privilegio, del pueblo que sufre contra la aristocracia que goza. (Las Provincias, Santiago, 21 de julio de 1890)

\section{LA PRÁCTICA DE LA DEMOCRACIA: EMANCIPACIÓN SOCIAL E IGUALDAD}

Solo ponderando esta oposición entre democracia y oligarquía como una de las distinciones ideológicas primordiales del PD, puede comprenderse de mejor modo una de las nociones cardinales en el proceso de reformulación conceptual hecha por Malaquías Concha. Me refiero al sintagma emancipación social. Para el abogado, esta noción englobaba el despliegue de instancias políticas, sociales y económicas que permitirán socavar las bases de la dominación oligárquica, dotando al pueblo -entendido desde una connotación de clase como los sectores medios y populares- de herramientas para la gestión de sus propios intereses. En ese registro, la democracia era concebida como una forma de "emancipar al pueblo de la esclavitud política". En síntesis, era la "tendencia igualitaria que nos lleva a la abolición de las prerrogativas sociales fundadas en la nobleza de la sangre, en la antigüedad de la familia, en títulos nobiliarios obtenidos del favor cortesano, y muchas veces en la simple posesión de la riqueza" (Concha, El programa 18-20).

Para concretar este proyecto de emancipación democrática de las clases populares, Concha desplegaba una serie de medidas. En primer término, y de manera previsible dada la conformación social de las filas del PD, una defensa del proteccionismo económico, medida insistentemente defendida 
por los sectores artesanales durante el siglo XIX (Grez, "La reivindicación"). La defensa del proteccionismo económico, más allá de sus dimensiones comerciales, era fundamental por sus implicancias sociológicas, en tanto permitiría la extensión del trabajo en todas las capas de la sociedad, en un registro que se hacía eco del discurso clásico de la sociedad ocupada (Díez), donde el trabajo adquiría una nueva dignidad y reconocimiento social. Otras medidas direccionadas en la emancipación social eran la abolición de la Guardia Nacional -demanda de larga data del movimiento obrero decimonónico-, en tanto usurpaba el escaso tiempo libre de los artesanos y la implementación de una educación obligatoria, gratuita, laica y útil ${ }^{3}$, la igualdad de los sexos, la subvención estatal a las sociedades obreras, teatros populares, bibliotecas y escuelas nocturnas, como lo propuso en su "Manifiesto político" cuando fue candidato a la diputación por Santiago (El Siglo XX, Santiago, 26 de febrero de 1894).

El horizonte normativo de la emancipación social era la consagración de la igualdad como nodo de la convivencia cívica en el marco de la república, que debía caracterizarse por la noción de fraternidad social ( $E l$ Siglo XX, Santiago, 26 de febrero de 1894). Como concepto polisémico, la igualdad también debía precisar sus usos y alcances, para sobreponerse a su homologación canónica a la idea de igualdad frente a la ley. Para Concha, las proyecciones de la igualdad se insertaban en otras lógicas, que podríamos consignar bajo lo que Rosanvallon denomina igualdad social, es decir, la igualdad de condiciones para un disfrute equitativo de la libertad (La sociedad). La igualdad, en un sentido amplio, era la precondición para el goce y la existencia real de ella. La existencia de la libertad sin igualdad correría el riesgo de volver a la primera insustancial y a la democracia una expresión vana pues "la libertad y la democracia no pueden subsistir sin la igualdad de condiciones" (Concha, El programa 23).

La igualdad de condiciones no debería confundirse con la igualdad material, precisión inevitable en un contexto donde, además de marcar distancias frente a la noción de igualdad manejada por el liberalismo,

Sobre la perspectiva educacional de Concha, véase Toro. 
debía establecer barreras de distinción respecto del discurso igualitario del socialismo, que comenzaba a institucionalizarse en el país (Fernández). Esta toma de distancia respecto del socialismo era crucial para los integrantes del PD, quienes tras liderar el motín de los tranvías en abril de 1888 fueron acusados por la prensa de difundir dicho ideario. Mientras un periódico constató que en esa jornada se apreciaban "los primeros síntomas del socialismo" (El Estandarte Católico, Santiago, 1 de mayo de 1888), otro sencillamente calificó los hechos de "una manifestación comunista" (El Heraldo, Santiago, 1 de mayo de 1888). Concha seńalaba que sus correligionarios no pretendían "nivelar las condiciones sociales arrebatando al rico lo que ha menester el pobre, ni tampoco reformar por la violencia nuestra organización actual, ni se predica la lucha de clases" (El Siglo XX, Santiago, 26 de febrero de 1894).

Eso no implicó que el discurso democrático no impugnase la desigualdad económica que contribuía a minar la convivencia social. "La democracia no pretende imponer a los miembros del Estado una igualdad artificial que la naturaleza no ha creado; pero reclama el derecho para todos los ciudadanos de medirse entre sí en condiciones iguales" (Concha, El programa 21). El problema residía justamente en que las desigualdades naturales eran profundizadas por "un medio social organizado por el privilegio en detrimento del mayor número". Como la desigualdad económica incidía en el deterioro de la convivencia cívica, era preciso desplegar medidas tendientes a detener el proceso de concentración de riquezas y pauperización de las condiciones de vida del país, pues "la desigualdad de fortunas, y la opresión que de ella nace, son un obstáculo y una amenaza para el afianzamiento de la democracia" (21).

Más allá de constatar el problema, el político e intelectual planteó una serie de medidas tendientes a solucionarlo. Así, por ejemplo, en $E l$ programa de la democracia se refirió al fenómeno de la colonización nacional en relación con la colonización extranjera defendida por el Estado, en el contexto de la ocupación de los territorios despojados al pueblo mapuche tras la campańa de anexión de la Araucanía. El acceso a la propiedad de las nuevas tierras no solo permitiría a los desposeídos transitar desde la 
condición de proletarios a la de propietarios, sino que en paralelo también debían establecerse disposiciones para evitar la concentración de tierra en manos de los latifundistas. Así, los terrenos baldíos del Estado debían ser de quien los ocupara, hasta un máximo de 30 hectáreas: "Devolvamos al pueblo lo que es del pueblo. La tierra ha sido dada a todos, no constituyamos un privilegio en favor de los ya favorecidos", sentenciaba Concha (El programa 372). Esta idea no quedó solo en los aspectos programáticos del PD, sino que Concha la llevó a las discusiones parlamentarias. La multiplicación de pequeños propietarios era la forma "más conveniente a mantener la paz social", pues no atender "las reclamaciones de la clase desposeída contra la clase que posee, es estimular y dar vida a todos los gérmenes perturbadores del orden social”. El gobierno debía entender que una política nacional de colonización en la Araucanía haría que cada ciudadano "comprenda que la seguridad de su fortuna y su propia seguridad está estrechamente ligada al buen orden social". "No habría salteadores en Chile si a cada hombre, sin distinción de clases, le hiciéramos amar la propiedad, dándole propiedad", concluía (Cámara de Diputados, 6 de julio de 1904, 445).

\section{Democracia E institucionalización Del CONFLicto SOCIAL}

Si bien estas dimensiones igualitarias resultan importantes en el programa del PD, no eran del todo innovadoras pues establecían una línea de continuidad con las demandas históricas del movimiento artesanal durante el siglo XIX. Donde sí es posible constatar cambios sustanciales y un giro novedoso en el argumento fue en la defensa de una noción original en el debate público chileno de la época, la de los derechos sociales que, en tanto tales, debían ser provistos por el Estado, postura de la cual Malaquías Concha fue uno de los principales defensores ${ }^{4}$. Dos desplazamientos argumentales son

\footnotetext{
4 Bastías da cuenta de esta transformación -la mayor injerencia del Estado en lo social en contraposición al liberalismo jurídico- en la cultura legal de la época, aunque, sorprendentemente, no menciona a Malaquías Concha en su trabajo.
} 
importantes en este punto: el imaginario de sociedad que subyace a esta reflexión y la misma conceptualización de Estado.

En primer término, hay una contraposición con el imaginario de sociedad propiciado por el liberalismo, aspecto que también nos permite entender las diferencias en las conceptualizaciones de la democracia. Si el discurso hegemónico del liberalismo a esas alturas del siglo XIX respecto de la constitución de la sociedad era una visión atomística, caracterizada por el individualismo (Rosenblatt 220-30), Concha opone una conceptualización organicista, inspirándose en Hippolyte Taine (Gasparini), donde "el cuerpo social es un organismo del cual los individuos no son sino células". La metáfora orgánica no era un mero recurso retórico: servía para establecer que lo más relevante no era el individuo y la primacía de sus intereses, sino el bien común del cuerpo social. Así, la función del derecho debía necesariamente cambiar de foco, centrándose en lo social, pues su tarea en el nuevo contexto del país era "contribuir al desarrollo armónico de las funciones sociales", funciones que el Estado debía garantizar (Concha, "El movimiento" 276-7).

El debate que sobre estos aspectos sostuvieron Malaquías Concha y Zorobabel Rodríguez en las páginas de la Revista Económica, a propósito de las proyecciones económicas del programa del PD, ilustra bien la contraposición de imaginarios societales con el liberalismo. Para Rodríguez, difusor del laissez faire y portavoz de la renovación liberal provocada en la década de 1870 en el seno del conservantismo chileno (García Naranjo), la realización eventual del programa del PD significaría anular la libertad del individualismo, es decir, "que cada individuo haga todo lo que le plazca sin más traba legal que el respeto a la libertad ajena” y poner, en su lugar, una paradojal libertad colectivista, aquella que buscaba imponer "la caprichosa voluntad de las mayorías”. El eje de la crítica de Rodríguez residía en que la tentación colectivista del PD, que inevitablemente conducía al socialismo, abrogaba al individuo, en tanto hacía "rebajar a la persona humana a la categoría de célula". El estatismo, corolario de un enfoque que rezumaba positivismo, paradójicamente anulaba la personalidad real del individuo y privilegiaba la lectura de que el Estado, "simple abstracción y modo de 
hablar de todos los individuos que viven dentro de sus fronteras, sí que es una personalidad real y un organismo viviente" (Rodríguez 346-60).

La nueva función del Estado promovida por Malaquías Concha resulta clave para la comprensión de su discurso sobre la democracia. Si la cuestión social es, siguiendo a Robert Castel (16), el momento en que una sociedad experimenta el enigma de su cohesión y trata de conjurar el riesgo de su fractura, suturar las fisuras sociales pasaba -en la lógica de Concha- por restituirle al Estado un rol protagónico, del cual el liberalismo lo había despojado. El nuevo papel que debería desempeñar el Estado sería relevante sobre todo en términos de la asistencia pública a los ancianos e inválidos. De este modo, la fraternidad social no debía estar relegada, como hasta entonces, a la noción de caridad individual (Ponce de León), sino ser asumida como una función primordial del aparato público.

Así, en El programa de la democracia, Concha instala el concepto de Estado providencia para aclarar de mejor forma su función de justicia reparativa en la sociedad $(186,241)$. Esta nueva reflexión sobre el rol estatal se correspondía con una comprensión sociológica del movimiento obrero como un cambio estructural en el panorama social chileno y la evaluación de las proyecciones políticas de un proceso considerado irreversible. La misma idea de emancipación social remitía, en el fondo, a un despliegue consciente de mecanismos políticos e institucionales de contención social por medio de la reducción de la desigualdad. La democracia, en este sentido, para Concha no era un mecanismo de selección de élites, sino una forma de convivencia en común, un modo de relacionarse que preservaba la república de la erosión de la desigualdad económica, conjurando institucionalmente el riesgo de la fractura social.

Por eso, el análisis sociológico del surgimiento y desarrollo del movimiento obrero en Chile de Concha se entiende desde la lógica de la amenaza que encerraba un proceso inevitable dadas las condiciones del capitalismo moderno. Las expresiones y metáforas escogidas para ₹establecer el fenómeno eran elocuentes: se trataba de un "movimiento sordo y persistente", "un vago rumor, precursor de los grandes cataclismos sociales", "un grave malestar a que es preciso poner eficaz y pronto remedio". El secretario del PD constataba 
una dinámica histórica que, desde su posición sociológica y positivista, adquiría el estatuto de una ley inexorable del desarrollo moderno: cuando la desigualdad económica y social se tornaban insostenibles, indefectiblemente ese malestar se expresaba en términos revolucionarios. De ahí que la nueva conceptualización del Estado propugnada por el PD fuese significativa, pues "el medio más eficaz de curar las grandes dolencias sociales consiste en apartar las causas que les han dado nacimiento combatiéndolas en su propia cuna" (Concha, "El movimiento" 265, 273).

La amenaza del conflicto social que Concha advirtió cuando se fundó el PD se hizo realidad en las primeras décadas del siglo XX, con el fortalecimiento del movimiento obrero, la escalada de las huelgas y el recrudecimiento de la represión estatal hacia ellas (DeShazo 159-74). Dos de estas fueron cruciales para probar, según Concha, la necesidad de reenfocar la acción estatal en la línea propuesta por el PD: la huelga portuaria de Valparaíso de 1903 y la huelga de la carne, en octubre de 1905 (Fernández Apablaza; Izquierdo).

Durante esos años Concha intensificó su labor parlamentaria, proponiendo una serie de medidas de contención social que buscaban mejorar las condiciones de vida de los sectores populares para así salvar al país "de la plaga del socialismo", amenaza plausible "desde que al pueblo se le excluye, de hecho, de toda injerencia en la riqueza y en el manejo de la cosa pública” (Cámara de Diputados, 1 de julio de 1897, 311). Entre las medidas de legislación social urgentes propuestas por el diputado por la zona penquista, se encontraban la eliminación del pago en fichas en las salitreras (Cámara de Diputados, 13 de noviembre de 1901, 288), el descanso dominical, la reducción de la jornada laboral y la sanción de una ley de protección contra los accidentes del trabajo (Cámara de Diputados, 15 de noviembre de 1904, 246-52).

La represión como mecanismo de resolución de conflictos escogida por la clase dirigente solo profundizaba la crisis social, pues "las reivindicaciones populares no han sido jamás contenidas por la fuerza". La represión contra los portuarios de Valparaíso en 1903 probaba la miopía política. Concha sostenía: 
Error profundo de nuestra oligarquía o de la clase plutocrática, que sienten amenazados su poderío o sus privilegios y que intentan resistir con las bayonetas el espíritu nuevo que preside el repartimiento de la riqueza según lo que corresponda al esfuerzo útil de cada ciudadano. Es peligroso jugar con fuego, y los que hoy confiándose débiles acuden a la fuerza armada para mantener sus monopolios de todo orden, no harán otra cosa que tener con su propia mano el cordón de seda en que se verían ahogadas sus prerrogativas cuando esa misma fuerza se diera cuenta de que en sus manos residía el orden social y el poder de tiranizar a los oligarcas. (El Ferrocarril, Santiago, 27 de mayo de 1903)

Y aunque el diputado Perfecto Lorca lo acusó en el Parlamento que con estas declaraciones estaba ensuciando "el estandarte sagrado de la democracia" cambiándolo por "el trapo negro de la sedición y de la revuelta" (Cámara de Diputados, 16 de junio de 1903, 239), el diputado del PD continuó interpretando esta dinámica de huelgas y represiones desde una perspectiva que planteaba la urgencia del procesamiento institucional del conflicto social por medio del rol protector del Estado frente a las relaciones entre capital y trabajo. La huelga de la carne, de octubre de 1905, donde se acusó a los parlamentarios del PD de instigar la manifestación, permitió nuevamente que Concha ilustrara sus tesis. Su perspectiva democrática insistía en la necesidad de mediación institucional del descontento popular, de modo de contener un potencial estallido revolucionario. "Lo único que hemos hecho nosotros es poner lápida a la cuestión social, que, con el fermento de las bajas pasiones, podría haber llevado al anarquismo a algunos elementos populares", aclaraba. "Fusilar al pueblo", la estrategia utilizada por la clase dirigente, solo agravaba el malestar e iba en la dirección contraria a su propuesta de contención social, que proponía una suerte de "solidaridad social entre los que dirigen y los que obedecen. Sin eso, no hay república, ni democracia, es exponernos a que en cualquier momento nos vamos a las manos; es la lucha entre los ricos y los pobres" (Cámara de Diputados, 31 de octubre de 1905, 97-8).

Lo anterior era complementado con un enfoque que apuntaba hacia el fortalecimiento económico del Estado, por medio de un cambio 
ideológico del argumento proteccionista decimonónico hacia un paradigma organicista, que incluía a referentes intelectuales tan diversos como Darwin, Marx y Spencer. Ese fue el tenor de la última obra importante de Malaquías Concha, La lucha económica, trabajo presentado en el IV Congreso Científico Americano de Santiago de 1908. Allí defendió el socialismo de cátedra y apoyó el aforismo marxista de que eran las condiciones materiales las que determinaban la existencia social. La supervivencia del Estado, en un contexto de lucha darwinista - prisma desde el cual Concha ahora interpretaba la evolución histórica- pasaba por abandonar el paradigma económico liberal, fortaleciendo la injerencia pública en la economía - desde la lógica del nacionalismo y el proteccionismo- y tendiendo hacia la industrialización, el único modo de defenderse de la dominación comercial europea. Por eso, si la lucha contemporánea más relevante era aquella expresada "en la expansión de las nacionalidades más perfectas y en la eliminación de las menos perfectas", la única solución era el proteccionismo, elevado a "una ley sociológica derivada de la lucha por la existencia entre las sociedades" (Concha, La lucha 68, 78).

\section{Reflexiones finAles}

Un análisis desde la historia conceptual de la democracia comprueba el carácter polisémico del concepto nodal de la modernidad política. Su centralidad en el discurso republicano y su posicionamiento como el horizonte de desarrollo político inevitable de las sociedades contemporáneas -aspectos consensuales en la cultura política del período- permitió el cuestionamientos de su vigencia efectiva en el contexto chileno decimonónico. Esta paradoja remite a uno de los aspectos constitutivos de la democracia como problema político. En efecto, la democracia no puede ser reducida a un conjunto de técnicas, procedimientos, mecanismos o instituciones, pues tiene una fuerte base ética, que la convierte en el "más exigente de los regímenes políticos". De allí que la democracia adquiere su vitalidad y capacidad de permanente renovación (Pasquino 67). 
Esta brecha insalvable entre la democracia como régimen político e ideal normativo fue justamente la condición de posibilidad del surgimiento del Partido Democrático en la década de 1880. En el contraste de ambas dimensiones, Malaquías Concha encontró una manera de establecer un discurso sobre la democracia, cuestionando su desplazamiento a manos de la oligarquía y estableciendo, mediante la enunciación del sintagma emancipación social, la posibilidad de recuperar un nuevo horizonte de desarrollo político, con un ideal igualitario y clasista de la democracia. Esta particular reagrupación conceptual y la atribución de contenidos éticos a la democracia, al asociarla con nociones de justicia social, fue el sello ideológico distintivo del PD en el sistema de partidos finisecular.

Pero además, la reivindicación de los intereses obreros y la instalación en el Parlamento de una agenda de leyes sociales como mecanismo que canalizara el descontento popular en un contexto de agudización de las tensiones laborales, fue una estrategia para distinguir al discurso democrático del PD desde la perspectiva de los sectores sociales interpelados. En ambos escenarios, la labor intelectual de Malaquías Concha fue central, pues cual innovador ideológico tomó una serie de demandas del movimiento obrero del siglo XIX, resignificándolas y actualizándolas doctrinalmente para distanciarse del discurso de la democracia liberal y de aquella narrativa reivindicadora de las clases populares ensayadas, todavía de manera incipiente, desde el socialismo. Sin embargo, aquello que fue rupturista terminó en el mediano plazo constituyéndose en parte del lenguaje común para cuestionar la democracia liberal desde los registros del radicalismo o el socialismo. Así, algunos de los planteamientos de Concha respecto de la democracia terminaron subsumidos en las agendas de otras colectividades, sobre todo en aquellas que demandaban un mayor protagonismo del Estado en la cohesión social, así como su injerencia en la economía. Sería parte de su legado al debate político del siglo XX. 


\section{Bibliografía}

Bañados, Guillermo. Sobre dos tumbas. Santiago: Imprenta La Universal, 1921.

Barber, Benjamin. Democracia fuerte. Madrid: Almuzara, 2004.

Barros, Luis y Ximena Vergara. El modo de ser aristocrático. El caso de la oligarquía chilena hacia 1900. Santiago: Ariadna, 2007.

Bastías, Manuel. "Intervención del Estado y derechos sociales. Transformaciones en el pensamiento jurídico chileno en la era de la cuestión social, 1880-1925”. Historia, vol. 1, n. ${ }^{\circ} 48,2015$, pp. 11-42.

Castel, Robert. Las metamorfosis de la cuestión social. Buenos Aires: Paidós, 1997.

Cid, Gabriel. "Entre el miedo y la esperanza: democracia y ciudadanía en el debate público chileno, 1822-1851". Conflictos y tensiones en el Chile republicano. Editado por Carlos Donoso y Pablo Rubio. Santiago: Universidad Andrés Bello/RIL, 2014, pp. 73-99

Concha, Malaquías. "El movimiento obrero en Chile". Revista Económica, n. ${ }^{\circ} 11$, marzo de 1888, pp. 263-84.

_. El programa de la democracia. Santiago: Imprenta de El Siglo XX, 1905.

_. $\quad$ El seguro de vida. Santiago: Imprenta Victoria, 1883.

_. La lucha económica, Santiago: Imprenta Cervantes, 1910.

Cruzat, Ximena y Ana Tironi. "El pensamiento frente a la cuestión social en Chile". El pensamiento en Chile. Santiago: Nuestra América Ediciones, 1987, pp. 127-51.

De Petris, Héctor. Historia del Partido Democrático. Posición dentro de la evolución politica nacional. Santiago: Dirección General de Prisiones, 1942.

DeShazo, Peter. Trabajadores urbanos y sindicatos en Chile: 1902-1927. Santiago: DIBAM/Centro de Investigaciones Diego Barros Arana, 2007.

Díez, Fernando. Utilidad, deseo y virtud. La formación de la idea moderna del trabajo. Barcelona: Península, 2001.

Donoso, Ricardo. Las ideas politicas en Chile. Santiago: Facultad de Filosofía y Educación Universidad de Chile, 1967.

El Demócrata. 23 de febrero de 1888, Concepción. 
El Estandarte Católico. 1 y 27 de mayo de 1888, Santiago.

El Ferrocarril. 29 de noviembre de 1888, Santiago.

El Heraldo, Santiago, 1 de mayo de 1888

El Siglo XX. 26 de febrero de 1894, Santiago.

Estellé, Patricio. "El Club de la Reforma de 1868-1871. Notas para el estudio de una combinación política en el siglo XIX”. Historia, n. ${ }^{9}$ 9, 1970, pp. 111-35.

Fernández Apablaza, Katherine. "De la toma de conciencia a la protesta social: la huelga portuaria de Valparaíso, 1903". Historia en Movimiento, n. ${ }^{\circ}$ 2, 2013, pp. 60-6.

Fernández, Camilo. "Ideología y redes políticas en los inicios del socialismo en Chile (1897-1900): los casos de la Unión Socialista y El Pueblo". Izquierdas, n.o 49, 2020, pp. 663-83.

Freeden, Michael. Ideologies and Political Theory: A Conceptual Approach. Oxford: Oxford University Press, 1996.

García Naranjo, Francisco. Zorobabel Rodríguez, un conservador moderno. Chile, 1864-1890. Morelia: Universidad Michoacana de San Nicolás de Hidalgo, 2010.

Gasparini, Éric. La pensé politique d'Hippolyte Taine: entre traditionalisme et libéralisme. Aix-en-Provence: Presses Universitaires d'Aix-Marseille, 1993

Godoy, Óscar Alfonso. Don Malaquías Concha, su vida, sus obras, su glorificación. Santiago: Imprenta Bellavista, 1923.

Goicovic, Igor y Nicolás Corvalán. "Crisis económica y respuesta social: el movimiento urbano artesanal, Chile 1873-1878”. Última Década, n. ${ }^{\circ} 1$, 1993, pp. 141-88.

Grez, Sergio. De la "regeneración del pueblo" a la huelga general. Génesis y evolución histórica del movimiento popular en Chile (1810-1890). Santiago: RIL, 2007.

- El Partido Democrático de Chile: auge y ocaso de una organización política popular (1887-1927). Santiago: Lom, 2016.

_. $\quad$ "La reivindicación proteccionista artesanal y la constitución del movimiento popular (Chile, 1826-1885)”. Historia Social, n. o 31, 1998, pp. 89-99

_. "Transición en las formas de lucha: motines peonales y huelgas obreras en Chile (1891-1907)". Historia, n. ${ }^{\circ} 33$, 2000, pp. 141-225. 
Held, David. Modelos de democracia. Madrid: Alianza, 2007.

Izquierdo, Gonzalo. "Octubre de 1905. Un episodio en la historia social chilena". Historia, n. ${ }^{\circ} 13,1976$, pp. 55-96

Jocelyn-Holt, Alfredo. "El liberalismo moderado chileno del siglo XIX". Estudios Públicos, n. ${ }^{\circ}$ 69, 1998, pp. 439-85.

Koselleck, Reinhart. "Un texto fundacional de Reinhart Koselleck. Introducción al Diccionario histórico de conceptos político-sociales básicos en lengua alemana". Anthropos, n. ${ }^{\circ} 223,2009$, pp. 92-105.

Koselleck, Reinhart. Futures Past. On the Semantics of Historical Time. Nueva York: Columbia University Press, 2004.

La Discusión. 20 de marzo, 1 de noviembre de 1888, Chillán.

Las Provincias. 21 de julio de 1890, Santiago.

Macpherson, Crawford Brough. La democracia liberal y su época. Madrid: Alianza, 2003.

Meynet, Alfredo. Estudio histórico de las reformas constitucionales de la administración Errázuriz Zañartu (1871-1876). Padre Las Casas: Imprenta San Francisco, 1946.

Nicholls, Nancy. "Intelectuales relevantes frente a la cuestión social en Chile (18901920): una minoría a favor del cambio". Historia, vol. 29, 1995-1996, pp. 295-356.

Orrego Luco, Augusto. La cuestión social. Santiago: Imprenta Barcelona, 1884.

Pasquino, Gianfranco. La democracia exigente. Madrid: Alianza, 2000.

Ponce de León, Macarena. Gobernar la pobreza. Prácticas de caridad y beneficencia en la ciudad de Santiago, 1830-1890. Santiago: Editorial Universitaria/Centro de Investigaciones Diego Barros Arana, 2011.

Rodríguez, Zorobabel. "El programa del Partido Democrático a la luz de los principios económicos", Revista Económica, n. ${ }^{\circ}$ 12, abril de 1888, pp. 34660 .

Rosanvallon, Pierre. La sociedad de los iguales. Barcelona: RBA, 2012.

_ $\quad$ Le peuple introuvable. París: Gallimard, 1998.

Rosenblatt, Helena. The Lost History of Liberalism. From Ancient Rome to the TwentyFirst Century, Princeton: Princeton University Press, 2018. 
Salazar, Pedro. La democracia constitucional. Una radiografía teórica. México: Fondo de Cultura Económica/UNAM, 2006.

Scully, Timothy R. Rethinking the Center. Party Politics in Nineteenth and TwentiethCentury Chile. Stanford: Stanford University Press, 1992.

Skinner, Quentin. "Rhetoric and Conceptual Change." Finnish Yearbook of Political Thought, vol. 3, 1999, pp. 60-73.

Soto, Serafín. Malaquias Concha, lider democrático. Santiago: Talleres Gráficos La Nación, 1951

Toro, Pablo. "Entre la continuidad y el cambio: Malaquías Concha y el Partido Demócrata ante la instrucción primaria en Chile a inicios del siglo XX". Anuario de la Universidad Internacional SEK, n. ${ }^{\circ}$ 4, 1998, pp. 107-18.

Turri, Enrique. Malaquías Concha, el político. Santiago: Editorial Universitaria, 1958.

Valenzuela, J. Samuel. "Orígenes y transformaciones del sistema de partidos en Chile”. Estudios Públicos, n. ${ }^{\circ}$ 58, 1995, pp. 29-38.

Yánez, Juan Carlos. Estado, consenso y crisis social. El espacio público en Chile 19001920. Santiago: DIBAM/Centro de Investigaciones Diego Barros Arana, 2003. 